\title{
Menstruating from the umbilicus as a rare case of primary umbilical endometriosis: a case report Pallavi V Bagade ${ }^{* 1}$ and Mamdouh M Guirguis ${ }^{2}$
}

\begin{abstract}
Address: ${ }^{1}$ Department of Obstetrics and Gynaecology, Wansbeck General Hospital, Woodhorn Lane, Ashington NE63 9JJ, Northumberland, UK and ${ }^{2}$ Department of Obstetrics and Gynaecology, North Tyneside General Hospital, Rake Lane, North Sheilds NE29 8NH, Tyne and Wear, UK

Email: Pallavi V Bagade* - palluvi@yahoo.com; Mamdouh M Guirguis - mamdouh.guirguis@northumbria-healthcare.nhs.uk

* Corresponding author
\end{abstract}

Published: 10 December 2009

Journal of Medical Case Reports 2009, 3:9326

doi:10.1186/1752-1947-3-9326

Received: 13 December 2008

Accepted: 10 December 2009

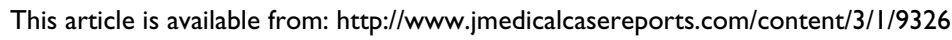

(C) 2009 Bagade and Guirguis; licensee BioMed Central Ltd.

This is an Open Access article distributed under the terms of the Creative Commons Attribution License (http://creativecommons.org/licenses/by/2.0), which permits unrestricted use, distribution, and reproduction in any medium, provided the original work is properly cited.

\begin{abstract}
Introduction: Endometriosis is a common gynecological condition and presents mainly with involvement of the pelvic organs. Extrapelvic presentations in almost all parts of the body have been reported in the literature. However, umbilical endometriosis that is spontaneous or secondary to surgery is uncommon and accounts for only $0.5 \%$ to $1 \%$ of all endometriosis cases.
\end{abstract}

Case presentation: A 35-year-old Caucasian woman presented with umbilical bleeding during periods of menstruation. Her umbilicus had a small nodule with bloody discharge. An ultrasound was performed and a diagnosis of possible umbilical endometriosis was thus made. The nodule shrunk in response to gonadotropin-releasing hormone analogues but continued to persist. The patient underwent a wide local excision of the nodule with a corresponding umbilical reconstruction. Histopathology confirmed the diagnosis of umbilical endometriosis. The patient was asymptomatic at follow-up, but nevertheless warned of the risk of recurrence.

Conclusions: Pelvic endometriosis is a common condition, but the diagnosis of primary umbilical endometriosis is difficult and differentials should be considered. This case strongly suggests that a differential diagnosis of endometriosis should be considered when an umbilical swelling presents in a woman of reproductive age.

\section{Introduction}

Endometriosis, a term first used by Sampson, is the presence of endometrial glands and stroma outside the uterine cavity and musculature [1]. It affects $7 \%$ to $10 \%$ of women in the reproductive age group [2]. It commonly occurs in the pelvic organs, especially the ovaries, the uterosacral ligaments and the pouch of Douglas. Women with endometriosis often present with dysmenorrhea, menorrhagia, pelvic pain and infertility.

Extragenital endometriosis is less common, but has been described in almost every area of the female body includ- ing the bowel, bladder, lungs, brain, umbilicus, and surgical scars [3]. Due to its varied presentations, endometriosis remains a difficult condition to diagnose and treat.

Umbilical endometriosis represents $0.5 \%$ to $1 \%$ of all cases of extragenital endometriosis. It usually occurs secondary to surgical scars, but very rarely presents as primary umbilical endometriosis $[4,5]$. We report one such rare case of spontaneous, primary umbilical endometriosis. 


\section{Case presentation}

A 35-year-old Caucasian parous woman presented to the clinic with symptoms of spontaneous and periodic bleeding from the umbilicus for four months. The bleeding would start two days before her menses and continue for the entire duration of her period. It was accompanied by pain and swelling in the umbilical area.

The patient had regular, heavy and painless menstrual periods and did not wish for any treatment for such. She had two previous spontaneous vaginal deliveries and had no history of abdominal pain, dyspareunia or infertility. She was not using any form of hormonal contraception. Her medical history was not significant and she never had any abdominal surgeries.

Clinical examination revealed that the patient had a $2 \mathrm{~cm}$ $\times 2 \mathrm{~cm}$ firm nodule at the umbilicus, which appeared to be covered by a reddish brown discharge. Suspecting that she had an infection, the patient was swabbed and given a five-day course of oral broad-spectrum antibiotics. She showed up on check up two months later with no relief of symptoms. She then underwent an ultrasound scan that showed a $15-\mathrm{mm}$ thin-walled cyst, approximately $5 \mathrm{~mm}$ below the skin surface. The key clinical feature that led to the correct diagnostic hypothesis of umbilical endometriosis was the temporal association of the bleeding with her menstrual period.

The patient was offered both medical and surgical management and she opted to have depot injections of Zoladex (AstraZeneca UK, Goserelin acetate, $3.6 \mathrm{mg}$ subcutaneously, monthly). The swelling continued to persist in spite of three doses of Zoladex, and the patient then requested surgical excision. The risk of recurrence and scar endometriosis were explained to her.

The patient successfully underwent excision of the nodule with accompanying umbilical reconstruction. Histology confirmed the diagnosis of endometriosis and revealed the presence of endometriotic glands with mucinous type metaplasia and extravasation of the mucinous secretion into the adjacent stroma (Figure 1). No epithelial atypia was seen and the excision appeared complete. The patient was seen six weeks after the surgery and found to be asymptomatic with a normal umbilicus. Before being discharged, the patient was again reminded of the risk of recurrence.

\section{Discussion}

The deposition of fragments of uterine endometrium in the skin is a well recognized, although uncommon, phenomenon ( $0.5 \%$ to $1 \%$ of extragenital endometriosis). Umbilical endometriosis was first described in 1886 and since then more than 100 cases have been described [4].

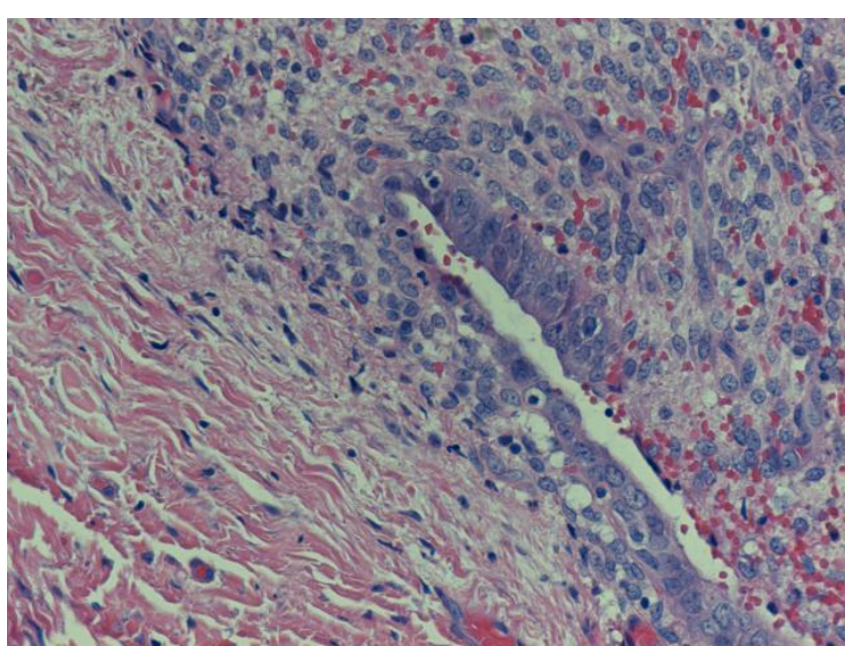

Figure I

Umbilical endometriosis: endometriotic glands with metaplasia of the mucinous type and extravasation of the mucinous secretion into the adjacent stroma.

Majority of these cases occurred secondary to surgical, commonly laparoscopy, scars. An umbilical endometriotic lesion without surgical history is a rare condition $[4,5]$. Some case reports have also described the presence of umbilical endometriosis during pregnancy [6].

There has been great speculation about the pathogenesis of this phenomenon and several theories have been proposed. Latcher has classified these theories into three main categories: the embryonal rest theory, which explains endometriosis adjoining the pelvic viscera by Wollfian or Mullerian remnants [4,5]; the coelomic metaplasia theory, which states that the embryonic coelomic mesothelium dedifferentiates into endometrial tissue under stimulus such as inflammation or trauma [7]; and the migratory pathogenesis theory, which explains the dispersion of endometrial tissue by direct extension, vascular and lymphatic channels, and surgical manipulation. Still others suggest cellular proliferation of endometrial cells from initial extraperitoneal disease along the urachus $[8,9]$. The real mechanism still remains a mystery.

These patients are usually in the reproductive age group and present commonly with swelling, pain, discharge or cyclical bleeding from the umbilicus. There may be associated symptoms of coexistent pelvic endometriosis. These lesions are usually bluish-black in colour and become painful, larger and bleed about the time of menses. They range in size from $0.5 \mathrm{~cm}$ to $3 \mathrm{~cm}$, but can enlarge to even more enormous sizes [4].

While the diagnosis is primarily clinical, magnetic resonance imaging (MRI) can be useful in evaluating patients 
with suspected endometriosis. Endometriomas appear homogeneously hyperintense on T1-weighted sequences [10]. MRI also has an advantage over laparoscopy for evaluating pelvic and extraperitoneal diseases, as well as lesions concealed by adhesions.

Histological findings are characterized by irregular glandular lumina embedded in the stroma with a high cellular and vascular component resembling the stroma of functional endometrium. A fairly recent study has suggested a distinctive dermatoscopic feature in cutaneous endometriosis -- that of comprising small red globular structures called 'red atolls' [11].

Differential diagnosis of umbilical nodules should include pyogenic granuloma, hernia, residual embryonic tissue, primary or metastatic adenocarcinoma (Sister Joseph's nodule), nodular melanoma, and cutaneous endosalpingosis.

Surgical excision of the lesion with sparing of the umbilicus is the preferred treatment of pelvic endometriosis [7]. In severe cases or in the presence of pelvic endometriosis, hormonal therapy in the form of danazol or GnRH analogues can be given to the patient [12]. In our case the lesion was excised and histology confirmed the diagnosis. Although simultaneous laparoscopy has been recommended for pelvic endometriosis, this was not done because our patient was asymptomatic. Although local recurrence is uncommon, the patient has been warned of the risk of scar endometriosis and of recurrence.

\section{Conclusions}

Endometriosis is a common gynaecological disease; however, primary umbilical endometriosis is very rare. Making a diagnosis is difficult and other causes of umbilical lesions should be considered. Surgical excision is the standard treatment of this condition.

\section{Abbreviations}

MRI: magnetic resonance imaging; GnRH: gonadotropin releasing hormone.

\section{Consent}

Written informed consent was obtained from the patient for publication of this case report and any accompanying images. A copy of the written consent is available for review by the Editor-in-chief of this journal.

\section{Competing interests}

The authors declare that they have no competing interests.

\section{Authors' contributions}

$\mathrm{PB}$ was a major contributor in collecting data, writing and preparing the manuscript. MG performed the surgical excision and was involved in editing the manuscript. All authors read and approved the final manuscript.

\section{References}

I. Sampson JA: Perforating hemorrhagic (chocolate) cysts of the ovary: their importance and especially their relation to pelvic adenomas of the endometrial type. Arch Surg 192I, 3:245.

2. Drake TS, Grunert GM: The unsuspected pelvic factor in the infertility investigations. Fertility and Sterility 1980, 34:27-31.

3. Markham SM, Carpenter SE, Rock JA: Extrapelvic endometriosis. Obstet Gynecol Clin North Am 1989, 16:193-219.

4. Latcher JW: Endometriosis of the umbilicus. Am J Obstet Gynecol 1953, 66:161-168.

5. Mann LS, Clarke WR: Endometriosis of the umbilicus. III Med J 1964, I 25:335-336.

6. Razzi S, Rubegni P, Sartini A, De Simone S, Fava A, Cobellis L, Fimiani $\mathrm{M}$, Petraglia $\mathrm{F}$ : Umbilical endometriosis in pregnancy: a casereport. Gynecol Endocrinol 2004, I8(Suppl 2): I |4-1 I6.

7. Schachter LR, Tash J, Olgac S, Bochner BH: Umbilical endometriosis. J Urol 2003, I 70:2388-2389.

8. Rubegni P, Sbano P, Santopietro R, Fimiani M: Case four: umbilical endometriosis. Clin Exp Dermatol 2003, 28:57I-572.

9. Ploteau S, Malvaux V, Draguet AP: Primary umbilical adenomyotic lesion presenting as cyclical periumbilical swelling. Fertil Steril 2007, 88(Suppl 6): 1674-1675.

10. Hartigan CM, Holloway BJ: Case report: MR imaging features of endometriosis at the umbilicus. Br J Radiol 2005, 78:755-757.

II. De Giorgi V, Massi D, Mannone F, Stante M, Carli P: Cutaneous endometriosis: noninvasive analysis by epiluminescence microscopy. Clin Exp Dermatol 2003, 28:3 15-3I7.

12. Purvis RS, Tyring SK: Cutaneous and subcutaneous endometriosis: surgical and hormonal therapy. J Dermatol Surg Oncol I994, 20:693-695.

\section{Publish with BioMed Central and every scientist can read your work free of charge}

"BioMed Central will be the most significant development for disseminating the results of biomedical research in our lifetime. " Sir Paul Nurse, Cancer Research UK

Your research papers will be:

- available free of charge to the entire biomedical community

- peer reviewed and published immediately upon acceptance

- cited in PubMed and archived on PubMed Central

- yours - you keep the copyright

Submit your manuscript here:

http://www.biomedcentral.com/info/publishing_adv.asp 